Revista de Estudios Histórico-Jurídicos

[Sección historia del derecho patrio]

XLII (Valparaíso, Chile, 2020)

[pp. 659-688]

\title{
INFLUJO DEL DERECHO INDIANO EN EL SISTEMA DE GObIERNO DURANTE la PATRIA VIEJA: ¿MONARQUía CONSTITUCIONAL?
}

[Influence of Spanish colonial law in the system of government during the 'Patria Vieja': constitutional monarchy?]

\author{
Felipe Westermeyer Hernández* \\ Sociedad Chilena de Historia del Derecho \\ y Derecho Romano
}

\section{RESUMEN}

El presente artículo analiza el sistema de gobierno vigente en Chile entre 1810 y 1814. Hasta ahora, los historiadores del constitucionalismo sólo han puesto el acento en la autonomía política. Este trabajo estudia y problematiza dicha tesis, al postular que el sistema de gobierno fue, de hecho, una monarquía sui generis, que poco tiene en común con el modelo tradicional de la monarquía constitucional.

Palabras Clave

Patria Vieja - sistema de gobierno - monarquia constitucional-autonomía política.

\section{AbStract}

This article analyzes the system of government in force in Chile between 1810 and 1814. Until now, historians of constitutionalism have only emphasized political autonomy. This work studies and problematizes this thesis, by postulating that the government system was, in fact, a sui generis monarchy, which has little in common with the traditional model of the constitutional monarchy.

\section{Key Words}

Patria Vieja - system of government - constitucional monarchy - political autonomy.

Recibido el 30 de abril de 2020 y aceptado el 3 de junio de 2020

\section{INTRODUCCIÓN Y ESTADO DE LA CUESTIÓN}

La influencia del derecho indiano en el primer constitucionalismo chileno fue estudiada hace más de veinte años ${ }^{1}$. Ahora queremos ahondar en ese influjo en el

* Universidad de Chile. Legum Magister in Rechtswissenschaft. Ruprecht-Karls-Universität Heidelberg. Ayudante de Historia del Derecho. Facultad de Derecho, Universidad de Chile, Chile. westermeyer.felipe@gmail.com. El autor agradece las sugerencias de los profesores Antonio Dougnac, Juan Carlos Frontera y Andrea Romano. Del mismo modo agradece la generosidad de los profesores Armando Cartes Montory y Eduardo Andrades Rivas, que me suministraron importantes materiales, varios de ellos inéditos. Asimismo, el apoyo prestado por el personal de Biblioteca de la Facultad de Derecho de la Universidad de Chile, especialmente por la señora Gioconda Pulgar. Todos los errores son única y exclusiva responsabilidad del autor.

${ }^{1}$ Dougnac Rodríguez, Antonio, El Sistema jurídico indiano en el constitucionalismo chileno durante la Patria Vieja (1810-1814), en REHJ., 22 (Valparaíso, 2000), pp. 225-266. 
sistema de gobierno, preguntándonos si hubo un sistema monárquico y, en caso afirmativo, si ese sistema fue una monarquía constitucional. Para ese objetivo calzan muy bien las palabras de Andrea Romano, quién señala que las constituciones son los más políticos de los textos jurídicos y los más jurídicos de los textos políticos; pues por una parte disponen y organizan y por otra parte enuncian un programa. En su calidad política, las constituciones usan un lenguaje que es menos técnico, más político y entendible para el ciudadano común que los códigos y leyes. Sólo así se puede lograr que posea las características de un contrato social ${ }^{2}$.

A este respecto, es necesario recordar que si los e n s a y o s c o n s t i t u c i o$\mathrm{n}$ a l e $\mathrm{s}$ se analizan con prescindencia de su contexto histórico y se interpretan con valores políticos y expectativas extrañas a su genesis, puede tener lugar una objetivación del texto histórico ${ }^{3}$, incorporándolo a modelos o tendencias a las que su contexto era ajeno o interpretando esas normas acorde al posterior devenir de los acontecimientos. Si bien ninguno de los textos constitucionales de la Patria Vieja se ha convertido en un mito o modelo, igual existe el riesgo de no entender adecuadamente la naturaleza de su regulación. En el proceso que parte en 1810 confluyen diversas corrientes ideológicas. En más de una intervención en el primer Congreso Nacional se citaron autores de la antiguedad clásica, del renacentismo italiano y filosofos políticos ingleses y franceses de la Edad Moderna ${ }^{4}$. En este trabajo nos centraremos en los textos constitucionales y antecedentes historicojurídicos relevantes que muestran algún influjo indiano en el sistema de gobierno.

Los límites de extensión de este trabajo nos impiden enumerar la cantidad de historiadores y juristas que se han ocupado de la Patria Vieja y el sistema de gobierno de ese cuatrienio. En general, gran parte de los autores se quedan en la idea de una mayor autonomía ${ }^{5}$, sin entrar en el tema del régimen de gobierno. Entre los que han profundizado en este punto, meritorio es el trabajo de Sergio Carrasco por su enfoque marcadamente jurídico ${ }^{6}$, la todavía inédita tesis doctoral de Eduardo Andrades, que explora las posturas realistas omitidas a lo largo de la historia republicana, ahondando en una serie de detalles y fuentes poco estudiadas ${ }^{7}$. Digno de mencionarse es el trabajo recopilatorio de Cristian Guerrero Lira, quien

2 Romano, Andrea, Cádiz en Italia. La recepción de la constitución de Cádiz en Italia y la Revolución Piamontesa, en Escudero, José Antonio (ed.), Cortes y Constitución de Cádiz. 200 años (Madrid, Espasa Calpe, 2011), III, p. 459.

${ }^{3}$ Ibíd., p. 459.

${ }^{4}$ Martínez de Rozas mencionó en su intervención en la ceremonia de inauguración del primer Congreso Nacional a Solon, Licurgo, Platón, Hobbes, Maquiavelo, Bacon, Grocio, Puffendorff, Locke, Bocalino, Hume, Gordon, Montesquieu, Rousseau y Mably. LeTELIER, Valentín (ed.), Sesiones de los Cuerpos Legislativos de la República de Chile. 1811-1848 (Santiago, Imprenta Cervantes, 1887), I, p. 40 [en adelante solo Sesiones de los Cuerpos Legislativos].

${ }^{5}$ Solo a modo de ejemplo, uno de los clásicos, Heise GonZÁlez, Julio, Años de formación y aprendizaje politicos: 1810-1833 (Santiago, Editorial Universitaria, 1978). De reciente publicación, InFANTE Marín, Javier, Autonomía, Independencia y República en Chile (1810-1828) (Santiago, Ediciones Centro de Estudios Bicentenario, 2014).

${ }^{6}$ Carrasco Delgado, Sergio, Génesis y vigencia de los textos constitucionales chilenos ${ }^{3}$ (1983, Santiago, Editorial Jurídica de Chile, 2002).

${ }^{7}$ Andrades Rivas, Eduardo, El ocaso del Reino (Tesis doctoral, Facultad de Derecho de la Universidad Nacional de Educación a Distancia, Madrid, 2019). 
aporta para estos efectos una interpretación de la primera Junta de Gobierno y del primer Congreso Nacional como nuevas de regencias, y desmitifica la fecha de apertura del segundo ${ }^{8}$.

Otra interpretación útil para efectos de este artículo es la formulada por Armando Cartes Montory, quien estudia el proceso emancipador desde las regiones, cuestionando la visión de un Estado homogéneo y unitario, mostrando como se dieron diversos intentos por instalar un sistema de gobierno que equiparase a Coquimbo y Concepción con Santiago, garantizando cierta autonomía en la defensa de sus intereses. El profesor Cartes ha puesto sobre la mesa las iniciativas destinadas a lograr un sistema de gobierno que resguardase las distintas identidades y regions existentes en el reino de Chile?. Algo más avanza Eduardo Cavieres, al reparar que los documentos redactados por Egaña en este período, si bien no rompen los pactos con el rey, constuirían una estructura republicana ${ }^{10}$.

Pero la interpretación más avanzada es la de Eric Palma, quien plantea que el sistema de gobierno que se intentó establecer fue el de la monarquía constitucional $^{11}$. Palma fundamenta su postura en que el Reglamento constitucional de 1812 era un texto jurídico y no político. Por ende, debe interpretarse de manera sistemática. Él sostiene que el art. 3 reconoce a Fernando VII como rey legítimo, lo coloca bajo la Constitución y, al mismo tiempo, es una claúsula de fidelidad a la Corona. Para él, esa norma quita efectos jurídicos a las normas promulgadas por autoridades peninsulares e indianas, cuya legitimación venía de autoridades elegidas por otros movimientos juntistas o por la Regencia. El cambio consiste, de acuerdo con este autor, en que el soberano es el pueblo y no el rey. Asimismo, cita también como prueba del monarquismo los artículos 8, 14, 24 y 27. Aparte de eso, transcribe una serie de documentos, especialmente algunos escritos de fray Camilo Henríquez, en los que se defiende las tesis de la compatibilidad del catolicismo con el proceso constituyente, del derecho del pueblo a ser feliz y del pueblo como titular de la soberanía. Por ser una obra de mayor alcance, ese autor se remitió a citar los textos, sin poder profundizar ni en un análisis de estos ni en otros aspectos de esa tesis ${ }^{12}$.

${ }^{8} \mathrm{La}$ fecha de apertura fue el 4 de julio, que otros autores han entendido como una muestra de simpatía hacia el proceso norteamericano, fue producto de la mera contingencia, toda vez que la apertura estaba programada para el día 23 de junio, pero debió postergarse debido a copiosas lluvias que cayeron en la capital durante una semana. GuERrERO LIRA, Cristian, El primer Congreso Nacional de Chile (1811) y sus documentos fundamentales (Santiago, Ediciones Centro de Estudios Bicentenario, 2011), pp. XXV-XXX y L.

${ }^{9}$ Cartes Montory, Armando, “Un gobierno de los pueblos...”. Relaciones provinciales en la Independencia de Chile (Valparaíso, Ediciones Universitarias de Valparaíso, 2014). Ahora como "Un gobierno de los pueblos...": la nación y las provincias en la Independencia de Chile (Santiago, Ediciones Centro de Estudios Bicentenario, 2018).

${ }^{10}$ Cavieres Figueroa, Eduardo, Discursos ilustrados y politicas reales. Los límites de la representación desde la base. Prólogo a la primera edición del libro de Armando Cartes "Un gobierno de los pueblos...”. Relaciones provinciales en la Independencia de Chile, cit. (n. 9), p. 41.

${ }^{11}$ Palma GonzÁlez, Eric, Estado Constitucional Liberal Católico en Chile (1812-1924): nueva historia constitucional (Santiago, Orion, 2011), pp. 247-270.

${ }^{12} \mathrm{Al}$ ser el objetivo de este artículo indagar en una tesis, nos toparemos con los documentos citados por Palma. 
Como ultimo punto a mencionar, destacable es la investigación del profesor argentino Juan Carlos Frontera, que analiza al menos diez proyectos constitucionales monárquicos en el mundo indiano en ese período ${ }^{13}$.

\section{NORMAS DE CARÁCTER ELECTORAL}

Esas normas son las primeras que reflejan la mentalidad jurídica y política imperante. Eso ya lo prueba la convocatoria a las elecciones del primer Congreso Nacional, efectuada por la junta de gobierno, con fecha 15 de diciembre de 1810 . Ese documento dice: "Los representantes de todas las provincias i partidos de Chile deben reunirse en esta capital para acordar el sistema que más conviene a su rejimen y seguridad i prosperidad durante la ausencia del rei" ${ }^{14}$. Entregó la organización de las elecciones a los cabildos, corporaciones que debían delegar al candidato electo un poder general de esa corporación, junto con instrucciones, lineamientos generales o una idea de lo que debían proponer y defender. Se trata de una convocatoria abierta, democrática en el sentido de que entrega a los vecinos representados en el cabildo la deliberación. Muestra de esa mentalidad la constituye el acta con los poderes de Bernardo O’Higgins y José María Benavente, diputados titular y suplente por Los Ángeles respectivamente, que no da especificación alguna acerca del sistema de gobierno a adoptar ${ }^{15}$. En cambio, el mandato otorgado a los diputados santiaguinos es algo más específico: "[...] todo lo que contribuya a la conservación $i$ aumento de nuestra santa relijión, felicidad del reino i defensa de nuestro amado soberano el señor don Fernando VII [...] para votar decisivamente $i$ hacer todo lo conveniente a los derechos de la relijión, el rei i la patria" ${ }^{16}$. Estos aspectos que revelan una concepción monárquica son las declaraciones en sí mismas y las instrucciones a los diputados. Indica que se ha convocado a esas elecciones ante "la triste situación del adorable Fernando VII" y "la necesidad de salvaguardar los derechos sagrados de la relijión i la conservación de la patria"17. Es decir, la convocatoria asume la monarquía como el sistema subyacente y el Congreso tendría, entonces, un carácter de regencia.

La existencia de esas actas es importante, pues prueba la predominancia de la concepción indiana de representación política ${ }^{18}$. Ésta se hacía por medio de un mandato que el mandatario, en este caso diputado, estaba obligado a respetar. Las decisiones de los representantess estaban orientadas por las instrucciones de la comunidad y no por las ideas políticas personales del delegado, quien debía

13 Ponencia titulada Autocracia y república en el primer constitucionalismo del Nuevo Mundo ¿Pervivencia o ruptura del derecho indiano?, presentada en el XX Congreso del Instituto Internacional de Historia del Derecho Indiano en septiembre de 2019 en la ciudad de Huelva, España (actas en prensa).

${ }_{14}$ Sesiones de los Cuerpos Legislativos, I, p. 9.

${ }^{15}$ Ibíd., pp. 27 ss.

${ }^{16}$ Ibíd., p. 29.

${ }^{17}$ Ibíd., p. 29.

${ }^{18}$ González Echeñique, Javier, Un estudio de influencias doctrinarias en la Independencia: el concepto de diputado o representante popular. 1810-1828, en Revista Historia, 6 (Santiago, 1967), pp. 151 ss. 
fidelidad al sentir de su comunidad, no pudiendo actuar contra las orientaciones que le habían dado y siéndole ilícito traspasar los límites de los poderes otorgados. La idea de representación vigente en ese momento, de carácter indiano e inspirada en el derecho civil, era que en determinados casos debía consultarse al pueblo mandante antes de votar. En este caso, la filiación política de O’Higgins, patriota exaltado, no tiene la relevancia que le habría otorgado un sistema de representación política liberal. Aparte de ello, él mismo fue parte del grupo de 12 diputados que presentaron su renuncia al Congreso Nacional, so pretexto del aumento de los diputados electos por la ciudad de Santiago, mientras esperaban las órdenes de los poderdantes, pues fueron elegidos en el entendido de que Santiago contaba con un menor número de representantes, como señalaba el acta de convocatoria ${ }^{19}$. Desde un punto de vista político, tal renuncia admite dos lecturas: una treta destinada a quitarle legitimidad a un órgano en el que su bando estaba en minoría, o como una forma de protestar ante la concentración del poder en Santiago, no prevista inicialmente. No entraremos a analizar la plausibilidad de estas interpretaciones. Lo relevante es que para efectos de esta investigación resulta claro que ninguna de esas interpretaciones pone en discusión la monarquía ni permiten entrever intenciones independestistas de carácter general: tanto la convocatoria de la Junta de Gobierno como el acta del Cabildo de Santiago reconocen la excepcionalidad del llamado a elecciones. La figura de Fernando VII es fuente de legitimación. Tal forma de entender la representación política fue tan fuerte que una de las causas del fracaso del proyecto federal del año 1827 fue la disconformidad de los cabildos ante las decisiones que sus representantes se veían obligados a adoptar sin contar ni con su anuencia ni sus instrucciones ${ }^{20}$. En 1827 nadie pensaba volver a la corona española; pero si existía respeto por los intereses de la comunidad.

\section{JURAMENTO ${ }^{21}$}

El juramento tiene en este caso un carácter simbólico. Su antecedente directo sería un acto eminentemente revolucionario ${ }^{22}$. Es el punto de partida de nuevas

19 Sesiones de los Cuerpos Legislativos, I, p. 53.

${ }^{20} \mathrm{El}$ mejor ejemplo de ello fueron los mandatos dados por los cabildos de Coquimbo, Curicó, Coelemu y Vicuña para el congreso federal. Más de uno de ellos fue declarado nulo por ese congreso. Al respecto, véase Sesiones de los Cuerpos Legislativos, XII, pp. 21, 22, 29 y 37.

${ }^{21}$ Esta institución ha sido algo descuidada por la historiografía jurídica nacional. Desde el derecho indiano y la historiografía constitucional comparada se ha estudiado en cuanto a su contenido y efectos jurídicos relacionados con el derecho constitucional, especialmente en cuanto primer fundamento del contrato social. Para estos efectos entendemos el juramento como la invocación a la Divinidad como testigo y garante de la verdad de un mensaje, una afirmación o una promesa, que conlleva la obligación de mantener un determinado estandar de conducta o ejecutar una determinada acción. El juramento implica en cuanto institución jurídica una obligación frente a otras personas, a un grupo y frente a la divinidad. Para efectos de este trabajo se han tomado como modelos el trabajo de Paolo Prodi y Marta Lorente. Prodi, Paolo (coord.), Glaube und Eid Glaube und Eid: Treueformeln, Glaubensbekenntnisse und Sozialdisziplinierung zwischen Mittelalter und Neuzeit Der Eid in der europäischen Verfassungsgechichte. Zur Einführung (München, Oldenbourg Verlag, 1993). LORENTE SARIÑENA, Marta, El juramento constitucional, en $A H D E ., 65$ (1995), pp. 585-632.

${ }^{22}$ Según Lorente, el antecedente directo de este juramento constitucional es el juramento 
instituciones: el Congreso Nacional y la Constitución escrita. Según las sesiones de los cuerpos legislativos asistieron al acto de inauguración del primer Congreso Nacional -en el que tuvo lugar el juramento constitucional- todos los órganos del reino: Real Audiencia, Real Universidad de San Felipe, Cabildo de Santiago e Iglesia. En otras palabras, se siguió el ritual que venía de la época indiana ${ }^{23}$, empezando con una misa y tomando luego juramento.

En ese sentido, los antecedentes y preámbulo siempre dan luces de las intenciones e ideas que orientan ese primer acto. En las actas consta como primer fundamento de la instalación del Congreso la crisis de la monarquía, producto del presidio de Fernando VII. En segundo lugar, menciona la necesidad de dar nuevamente unidad a los vecinos del reino, divididos ante la manera de enfrentar la crisis. "Reanimados con la memoria de sus leales projenitores i noble presentimiento de vasallaje más feliz", por lo que se buscó un p u n t o d e u n i d a d. Otros motivos fueron la seguridad, los derechos de la religión, los homenajes del soberano y el deber de conservar la patria. El acta de instalación ratifica luego que la única autoridad que reconocen es al rey y que en ausencia de éste consideraban que estaba mejor resguardo de la corrupción por un gobierno de siete patriotas, que convocó a ese primer Congreso Nacional ${ }^{24}$. Este acto lo concibe como una institución de encuentro y una instancia de diálogo. La legitimidad de esta decisión descansaba en el monarca y en el pueblo formado por los vecinos. Es decir -valga la redundancia-, aquí hay una alusión tanto al monarca como a la comunidad en cuanto actores del proceso constituyente.

Cada uno debió prestar cuatro juramentos: "¿Jurais la santa relijión católica, apostólica romana sin admitir otra en este reino?", "¿Jurais ser fieles a Fernando VII de Borbón libre de toda dependencia extranjera?" "¿Jurais defender el reino de Chile i sus derechos contra sus enemigos interiores i exteriores, i para conservar la mayor union?" y finalmente " ¿Jurais desempeñar fiel i legalmente la importante comisión que el reino ha puesto a vuestro cuidado?". Todos respondieron: "sí, juramos". El presidente respondió luego: "y si asi lo hiciereís, Dios os lo premie o sino os lo demande" 25 . La respuesta de todos fue un amén, subiendo los diputados de dos en dos a tocar el libro de los Evangelios que estaba puesto en el altar.

Como ya se dijo en el párrafo anterior, el juramento marcó un punto de partida. Ni el mundo indiano ni Chile poseían una constitución escrita, ni estaban familiarizados con un órgano como las Cortes. Lo que sí existía desde muchísimo antes era la institución del juramento, que reflejaba el sentir y la mentalidad jurídica de una época, constituyendo su contenido un límite al ejercicio de la soberanía ${ }^{26}$ :

de la sala del juego de pelota en Francia. Lorente Sariñena, Marta, cit. (n. 21), p. 591.

${ }^{23}$ Concha Márquez de la Plata, Sergio, De las juras reales a las juras constitucionales: la continuidad de un ceremonial en Chile, en GuZMÁN BRTTO, Alejandro (ed.), El Derecho de las Indias occidentales y su pervivencia en los Derechos patrios de América. Actas del Decimosexto Congreso del Instituto Internacional de Historia del Derecho Indiano (Valparaíso, Ediciones Universitarias de Valparaíso, 2010), II, pp. 941-953.

${ }^{24}$ Sesiones de los Cuerpos Legislativos, I, p. 32.

${ }^{25}$ Ibíd., p. 33

${ }^{26} \mathrm{La}$ concepción del juramento en el derecho público, como un acto que establece los límites a la soberanía, implicaba ciertas limitaciones para el legislador y el constituyente. Una de ellas 
continuar con las bases del régimen de gobierno - esto es, conservar la monarquía y el catolicismo-, el carácter de reino de Chile y el rey como factor de unidad entre los miembros del reino y frente a los otros reinos de la Corona. Así se entiende el hecho que el Congreso Nacional decidiese no mandar representantes a Cádiz. Lo que hay acá es la manifestación del deseo de seguir siendo parte de la Corona hispana, reiterando que Chile es un reino distinto de los peninsulares. Aquí lo novedoso es el reconocimiento de los derechos de Chile. El segundo juramento habla de Fernando VII libre de toda dependencia extranjera. Tal petición debe entenderse en conjunto con el juramento anterior. Muestra, por una parte, a una comunidad con derechos frente al monarca -a quien no se desconoce- y un interés en conservar su independencia dentro de la Corona, y por otra, la preocupación por no aceptar a un rey sometido por diversas vías a Napoléon, inquietud que no fue exclusiva del movimiento juntista chileno ${ }^{27}$. Este juramento muestra la intención de un monarca al servicio de sus súbditos y abre las puertas a buscar otra persona como rey si Fernando VII volvía políticamente derrotado. Tras esa inquietud hay una concepción de poder basada en el contrato callado. El pueblo tiene derecho a exigir un mínimo: un rey libre. El tercer juramento tiene una serie de concordancias con la declaración de los derechos del pueblo de Chile y con las ideas expresadas por Camilo Heríquez en la homilía de la liturgia previa a la instalación, que se verá después.

En cuanto al contenido del juramento, resulta llamativo no el hecho que éste haya fijado los límites de la soberanía y de las facultades del Congreso, sino que dentro de esos márgenes haya otorgado a sus miembros completa libertad. No hubo mención alguna a sus labores. Tal falta de directrices en cuanto a las tareas de este nuevo órgano se ve parcialmente suplida en el juramento que al día siguiente de la instalación debieron prestar prelados, jefes militares y corporaciones. Recién en ellas se habló de tareas legislativas y constituyentes. El texto de este segundo juramento habla por si sólo: “ ¿Reconoceís en el congreso de los diputados de este reino la suprema autoridad que en nombre de Fernando VII representa? ¿Jurais obedecer sus decretos, leyes $i$ constitución que se establezcan según los santos fines que se ha reunido, i observarlas inviolablemente?" ${ }^{28}$. En consecuencia, subordina jurídica y políticamente a la Iglesia, al ejército y a las corporaciones a la constitución escrita y al nuevo Congreso, y ratifica que es éste el que ocupa el rol central del monarca: durante toda la monarquía indiana, órganos y corporaciones estaban supeditados a él. Todo el poder de la administración tenía como origen la figura del rey, y todos sus organismos estaban sujetos a derecho. En lo estrictamente jurídico,

era la imposibilidad de derogar leyes si tal acto implicaba conculcar los límites establecidos en el juramento. Dicha idea se retrotrae por lo menos a Jean Bodin. QUAGIONI, Diego, Giuramento e sovranita. Il Giuramento como limite de la sovranita nella Republique di Jean Bodin, en PRODI, Paolo, cit. (n. 21), pp. 97-111.

${ }^{27}$ Lo mismo sucedió en las Cortes de Cádiz: dieron principio el 24 de septiembre de 1810 y terminaron el 20 de septiembre de 1813. Diario de Sesiones de las Cortes Generales y Extraordinarias (Madrid, Impr. José A. García, 1870), I, pp. 246-256.

${ }^{28}$ Sesiones de los Cuerpos Legislativos, I, pp. 33-35. 
este juramento puede entenderse, entonces, como la reiteración del principio de juridicidad, acorde a Rec. Ind. 2, 1, 9.

El tercer aspecto monarquista, aunque solo sea de caracter protocolar, es el acuerdo de que el Congreso debía recibir el trato de "Alteza y los honores de Capitán General del Ejército". El tratamiento de "Alteza" es inherente al monarca desde la dictación de la "Instrucción para el gobernador y oficiales reales sobre el gobierno de Indias”, que Colón en su calidad de virrey debía observar ${ }^{29}$.

\section{Discursos legitimadores del Congreso Nacional}

$\mathrm{Al}$ nacer una nueva institución siempre es importante analizar los fundamentos que se dan para su instalación. Ellas reflejan las ideas y la idiosincracia jurídica que está detrás de esa reforma. En esta figura hubo una mezcla de tradición y cambio.

El primer discurso fue el sermón dado en la liturgia previa al juramento de los diputados. Dicha prédica fue pronunciada por fray Camilo Henríquez, con la intención de demostrar la compatibilidad entre el llamado a elecciones por un Congreso Nacional, votar en ellas, darse una nueva constitución y el catolicismo. Fue una respuesta teológica a sectores del clero que se mostraban escépticos frente a esta iniciativa, y una contestación política a los grupos realistas. Henríquez sostuvo que, acorde con la equidad natural, era siempre legítimo combatir el despotismo. Por ello, "la equidad natural, elevada como un juez integérrimo e inflexible sobre los imperios i las repúblicas, miró con igual complacencia a estas dos formas de gobierno" 30 . La religión recomienda a los súbditos la obediencia a los gobiernos establecidos ${ }^{31}$. Sin embargo, Henríquez admite a reglón seguido que hay momentos en los que los Estados caen en crisis. Una de ellas es el caso en el que la metrópoli cae en manos de un conquistador extranjero, ante lo cual las provincias pueden resistir. Esa opción es legítima frente a la disolución y el exterminio ${ }^{32}$. En aras de ello es que existe, según él, una justicia inmutable e inmortal, anterior a todos los imperios, que otorga al hombre derechos eternos. Tales son "principalmente la facultad de defender $i$ sostener la libertad de nuestra nación, la permanencia de la relijión de nuestros padres $i$ las propiedades $i$ el honor de las familias" ${ }^{33}$. Esos bienes solo se podrán proteger mediante "una constitución conveniente a las actuales circunstancias de los tiempos, esto es, un reglamento que determine el modo con que ha de ejercerse la autoridad pública" 34 .

Para eso Henríquez formuló tres proposiciones: "los principios del catolicismo autorizan al Congreso Nacional a redactar una nueva constitución; la nación chilena tiene derechos que la autorizan a dictar una constitución y nuevas leyes que aseguren su libertad y felicidad y que entre los individuos y el Congreso Nacional existen

\footnotetext{
${ }^{29}$ Martiré, Eduardo, Algo más sobre el derecho indiano (entre el ius commune medieval y la modernidad), en AHDE., 73 (Madrid, 2003), p. 260.

${ }^{30}$ Sesiones de los Cuerpos Legislativos, I, p. 34.

${ }^{31}$ Ibíd., p. 34.

32 Ibíd., p. 34.

${ }^{33}$ Ibíd., p. 34.

${ }^{34}$ Ibíd., p. 34.
} 
deberes. Para unos obedecer y para los otros el amor a la patria"35. La primera de sus proposiciones fue fundamentada en el Libro de Macabeos, y postula que el catolicismo, ante circunstancias extremas, autoriza la rebelión y la defensa de los valores propios. En el caso concreto, el reino de Chile se daría una nueva constitución, lo que representaría una medida de defensa de sus valores y principios ante las adversas circunstancias. Hasta este punto, su prédica se encuadra dentro de los presupuestos de la monarquía indiana.

Henríquez fundamentó la segunda proposición en la situación de la monarquía católica en España. Instituir un Congreso no significaba dejar de amar al rey. En esas circunstancias lo único que se podía hacer era resguardar la libertad, pues Chile y la nación estaban separados del monarca. Es así como llega a plantear que "el sentimiento de estos derechos vive inmortal en nuestros corazones [...] I esto es lo que nos inspira la confianza de que, si la divina providencia restituyese al señor don Fernando VII, o a su legitimo sucesor a la España, o lo condujese a alguna de las rejiones de América, nos admitiera gustoso a su sombra bajo los pactos fundamentales de nuestra constitución" ${ }^{36}$. Ese planteamiento se compatibiliza muy bien con la idea de que el Reglamento Constitucional de 1812 lo que desconoce no es la monarquía, sino las órdenes emanadas de autoridades de otras regiones de la corona.

Respecto a la última de sus proposiciones, dijo Henríquez que la más alta potestad del Congreso era dictar una constitución y dentro de ella, la que se refiere al poder ejecutivo: "El artículo más importante de esta constitución es el establecimiento de un poder ejecutivo $i$ la organización del gobierno" ${ }^{37}$. Solo así se puede evitar la anarquía y la tiranía. Es obligación obedecer a los buenos gobiernos, inspirados en el amor a la patria. Reconoce, precisamente, que el mayor problema de ese momento era el vacío de poder derivado de la ausencia del rey.

El discurso tras el juramento de los nuevos diputados estuvo a cargo de Juan Martínez de Rozas. Sus palabras tuvieron menos de carga político-filosófica y mucha más de pragmatismo. Denunció la crisis de la monarquía como consecuencia de la decadencia de España y su gobierno ${ }^{38}$. Con duras palabras fustigó el actuar de la elite peninsular y del gobierno de Carlos IV. "Un privado absoluto en veinte años de despotismo degradó a los descendientes del Cid". Por ello sostiene que " $a$ una voz todos los vivientes en Chile protestan que no obedecerán sino a Fernando" 39 . Martínez de Rozas informó que su idea de gobierno era que el Congreso debía estar al servicio del soberano, "primer individuo de la patria, a la seguridad de esta $i$ a la prosperidad interior, a la conservación de su honor, que solo puede conseguirse por la integridad de las relaciones exteriores" 40 .

La sesión de instalación finalizó con la intervención del presidente de la nueva corporación, Juan Antonio Ovalle. Él fundamentó la legitimidad del Congreso

\footnotetext{
${ }^{35}$ Ibíd., p. 35.

${ }^{36}$ Ibíd., p. 36.

37 Ibíd., p. 37.

${ }^{38}$ Ibíd., p. 38.

${ }^{39}$ Ibíd., p. 39.

${ }^{40}$ Ibíd., p. 39.
} 
en el derecho natural y el de gentes ${ }^{41}$, y cuya instalación no debilitaba per se al monarca. Prueba de ello era el juramento que los nuevos diputados habían pres$\operatorname{tado}^{42}$, y que probaban la fidelidad al monarca y dejaban claros los límites de la acción del Congreso. Ovalle cita entre los preceptos e ideas vinculantes por medio de esos juramentos las ideas ilustradas de fomento de la ciencia, divulgación del conocimiento y fortalecimiento de las actividades económicas, a las que agrega el amor al prójimo y los preceptos de los concilios de Constanza, Basilea y Trento.

Del mismo modo, justificó los derechos del monarca en la conquista de América. De los derechos imprescriptibles del monarca derivarían todas las mercedes del continente. Ovalle vinculó el derecho de propiedad antes mencionado por Camilo Henriquez con la defensa de la monarquía, fundamentándolo en el "ne rerum dominia in incerto sint" ${ }^{43}$. Su segundo argumento para la instalación del Congreso fue la obligación moral de defender la propia vida y hacer todo lo necesario para ello a nivel gubernamental. Entre las medidas de defensa estaba la reorganización del aparato estatal y la redacción de una constitución ${ }^{44}$.

Se puede aventurar que toda la argumentación expuesta en el acta de instalación del Congreso Nacional es indiana. La teoría política del derecho indiano ya poseía en el siglo XVII aspectos contractualistas, también conocidos como pactismo escolástico. En el siglo XVIII ya convivían distintas corrientes iusfilosóficas en América: iusracionalismo, ilustración y escolástica ${ }^{45}$. Autores de esas corrientes, con distintos fundamentos, sostuvieron la misma idea de que el poder de los reyes viene dado por el pueblo. En resumidas cuentas, en Indias se sostuvo que el poder de la autoridad era dado por la voluntad humana y no la divina.

De acuerdo al tratadista limeño Francisco Ugarte de la Hermosa y Salcedo, inspirado por el derecho indiano, los hombres forman la sociedad civil para sobrevivir y apoyarse mutuamente, superando el estado de la naturaleza, dándole facultades a magistrados, príncipes y reyes, pues los hombres necesitan una autoridad ${ }^{46}$. Los hombres forman la sociedad civil y a ella le introducen normas y principios, entre ellos el sistema de gobierno. De esa manera surge la monarquía, en la que el reino pertenece a la comunidad, no al monarca ${ }^{47}$, a quien se le entrega el poder mediante el pactum subjectionis, pero conservando la república derechos irrenunciables respecto de él. Esas obligaciones constituyen obligaciones mayestáticas y límites al ejercicio del poder ${ }^{48}$. Entre ellas estaba hacer lo que es lícito y justo, ejercer el poder

${ }^{41}$ Ibíd., p. 42.

${ }^{42}$ Ibíd., p. 42.

${ }^{43}$ Ibíd., p. 42.

${ }^{44}$ Ibíd., p. 42.

${ }^{45}$ Pérez Perdomo, Rogelio, Tradicionalismo y modernismo en la filosofía del derecho del siglo XVIII español, en Derecho PUCP. Revista de la Facultad de Derecho, 26 (Lima, 1968), pp. 39-46. Aunque centrado en la realidad rioplatense, la descripción hecha es aplicable al resto del mundo indiano: PeÑa-Peñaloza, Roberto, Los derechos naturales del hombre en la ideología del siglo XVIII rioplatense, en RChHD., 16 (Santiago, 1990-1991), pp. 193 ss.

${ }^{46}$ Dougnac Rodríguez, Antonio, Un jurista indiano en la ruta de Hobbes, en RChHD., 17 (Santiago, 1992), p. 33.

${ }^{47}$ Ibíd., p. 36.

${ }^{48}$ Ibíd., p. 36. 
personalmente, administrar justicia, legislar, honrar a los súbditos premiando a los que se lo merecen, dar el buen ejemplo, atender al mérito y protegerlos. En la otra parte del pacto, los súbditos estaban obligados a obedecer. El único caso en que estaban eximidos de esa obligación era el de la inobservancia de las normas y principios que limitaban el poder real. En ese caso estaba autorizado el ejercicio del derecho a rebelión, pues la monarquía había devenido en una tiranía ${ }^{49}$. La obra del tratadista Ugarte no previó, al parecer, el caso de ausencia del monarca, pero sus postulados dan orientaciones frente a esta situación.

La mentalidad indiana partía de la base de que la Divinidad había entregado ese poder a los hombres y éstos al gobernante. Decidoras son las palabras formuladas por uno de los precursores del constitucionalismo mexicano, el jurista Francisco Primo de Verdad y Ramos, al senalar que: "los soberanos siempre han estado autorizados por Dios, que ha escogido al pueblo como instrumento para elegirlos" 50 . En ese sentido, sostiene Peña Peñaloza que en el siglo XVIII se afirmó que si el rey convertía su poder legítimo en una tiranía, el pueblo podía hacer uso de su legítima defensa. Esa doctrina se actualizaría y debatiría en $1810^{51}$. El derecho de resistencia es consecuencia del incumplimiento del pactum subjectionis.

En este punto se puede objetar la tesis de la monarquía constitucional en el hecho de que se trata de documentos que surgen en los albores del proceso independentista, en un momento en el que se necesitaba resguardar las apariencias y en el que la única fuente de legitimidad política seguía siendo el monarca. Ello habría cambiado con la irrupción de José Miguel Carrera en el acontecer político chileno, cuyo actuar habría sincerado las intenciones políticas de gran parte de Chile.

\section{UN DOCUMENTO REDACTADO EN 1811 Y REFORMADO EN 1813}

El reparo arriba mencionado se desvanece, en nuestra opinión, considerando la existencia de la "Declaración de los Derechos del Pueblo de Chile" 52 . Ese documento no ha recibido por parte de la historiografía constitucional la atención que merece, no obstante representar el sentir de la Junta de Gobierno tanto en 1811 como en 1813. Se trata de un documento de carácter político que fue presentado por su autor, Juan Egaña, y luego modificado a petición de ésta. La antedicha declaración posee una línea argumentativa muy similar a la expuesta en el acto de instalación del primer Congreso Nacional; es más, en ella se pueden ver una serie de coincidencias entre las ideas de Camilo Henríquez, Juan Antonio Ovalle y Juan Egaña. Este acuerdo contiene los siguientes puntos: i) el pueblo de Chile se gobernará por una constitución justa, liberal y permanente, y será soberano para dirigir sus relaciones exteriores hasta que un Congreso establezca un nivel general de seguridad y unión mutua; ii) Fernando VII, o la persona física o moral que señale el Congreso, será jefe constitucional de toda la nación, y sus derechos,

\footnotetext{
${ }^{49}$ Dougnac Rodríguez, Antonio, Un jurista indiano, cit. (n. 46), pp. 36 ss.

${ }^{50}$ Soberanes FernÁNDEZ, José Luis, El pensamiento constitucional en la Independencia (Ciudad de México, Editorial Porrúa-UNAM, 2012), p. 75.

${ }^{51}$ Peña-Peñaloza, Roberto, cit. (n. 45), p. 195.

52 Sesiones de los Cuerpos Legislativos, I, pp. 209 ss.
} 
regalías y preeminencias serán declarados por el dicha corporación; iii) Chile será una sola nación con los pueblos españoles en ese Congreso, constituído de modo libre e igual; iv) la religión es la católica romana; v) por último, todo individuo natural de cualquiera de los dominios de la monarquía española, prestando el juramento constitucional, deberá reputarse chileno y cumpliendo con los deberes de ciudadano, es apto para los ministerios del Estado ${ }^{53}$.

Este acuerdo es una opción preferente por los reinos que componen la Corona, y no descarta ni la monarquía ni la persona de Fernando VII. Por el contrario, hay una opción clara por la primera como sistema de gobierno. Asimismo, ratifica que todo el poder viene del pueblo. Se puede observar un interés indiscutido por una constitución escrita y en un monarca como jefe constitucional. Importante es poner de relieve que la idea de j e f e es típica de constituciones monárquicas como la francesa de 1791, que en su capítulo IV utiliza esa voz para referirse a las funciones del rey.

Con esos antecedentes puede colegirse que hay un interés por continuar, al menos en parte, con el sistema de unión real que había caracterizado a la monarquía indiana ${ }^{54}$. La constitución escrita es la novedad, que en sí contendría una serie de instituciones comunes a todos los reinos que quedasen sujetos a ella. Los fundamentos de la declaración pueden resumirse en la necesidad de mejorar la seguridad exterior del reino ante las amenazas provenientes de Europa, y de ese modo evitar la guerra; en la constatación de lo difícil que era ejercer la soberanía de manera aislada; en la necesidad de llegar a un acuerdo con Europa o parte de ella; la idea de que los pueblos españoles pueden elegir libremente a su gobierno o sus gobernantes y en el que los virreyes de México y Lima carecían de legitimidad, pues ésta les era dada por el monarca y ella de momento no existía y, sobre todo, en la idea de que la reunión de América en un Congreso, ya sea de la nación o de parte de ésta, le dará mayor preponderancia a la América hispanoparlante en el concierto internacional $^{55}$. Es decir, hay una clara inclinación hacia la monarquía regulada en la constitución, en la que se reitera que el poder constituyente radica en el pueblo, que en este documento es la población que habita los reinos de América ${ }^{56}$. Relevante es destacar que estos documentos hablan del pueblo como el principal eje articulador del poder constituyente, e igualmente es importante destacar que es el pueblo en el Congreso el que declara y reconoce los derechos y regalías, no el rey. Por ende, no se puede hablar de una constitución otorgada.

\section{El SIGNificAdo de LA VOZ N A C I Ó N A COMIENZOS DEL SIGLO XIX}

Un aspecto que a menudo es pasado por alto es el significado de ciertas palabras. $\mathrm{N}$ a c i ó $\mathrm{n}$ es un concepto cuyo significado ha variado enormemente en

\footnotetext{
${ }^{53}$ Ibíd., pp. 209-211.

${ }^{54}$ Vease ZorRaQUín BeCú, Ricardo, La organización política argentina en el periodo hispano ${ }^{4}$ (1962, Buenos Aires, Editorial Perrot, 1981).

55 Sesiones de los Cuerpos Legislativos, I, pp. 209-210.

${ }^{56}$ Tal idea no pasa de ser una reiteración de lo sistematizado por los profesores Dougnac, Peña-Peñaloza y Soberanes.
} 
los últimos dos siglos. Debe tenerse presente que fue usado desde la Antigüedad para designar a grupos culturalmente homogéneos ${ }^{57}$. A partir de la Revolución Francesa, era n a c i ó n una unidad dada por una organización política ${ }^{58}$. Así fue como Sieyes la definió como "Un cuerpo de asociados que viven bajo una ley común y están representados por la misma legislatura" 59 . Es un concepto descriptivo del estado monárquico de la Europa occidental y central. Dicha definición calza con el Estado indiano. Aparte de ello, por diferencias de traducción entre el latín y el francés, se hizo sinónimos a nación y Estado, es decir, un conjunto humano sometido a la autoridad del príncipe. El uso de la palabra en cuestión, en la década de 1810 en el mundo iberoamericano, alude a una organización existente, no a la posibilidad de fundar un nuevo Estado. A lo más, se lo puede entender como un protonacionalismo, entendiendo éste como la conciencia de pertenecer o haber pertenecido a un determinado Estado ${ }^{60}$. El concepto de $\mathrm{n}$ a c i ó n sobre la base de una comunidad que ya existe y cuyos factores de unión serán el idioma, la religión o la raza y que es la base social para fundar un Estado no corresponde a este período ${ }^{61}$. Por eso sostenemos que el uso de la palabra acá se acerca más a la justificación de una reforma en la organización del Estado, que ya existe, que a la constitución de uno nuevo. El uso de este término en la "Declaración de los Derechos del Pueblo de Chile" alude a un estado monárquico, a un derecho común y también a un monarca. No representa deseo de ruptura, sino de reforma dentro de la Corona.

\section{RELACIÓN CON OTROS ESTADOS MIEMBROS DE LA CORONA}

Otro documento a considerar en este sentido son las "Instrucciones del enviado de Chile ante la junta provisional de las provincias del Río de la Plata”, en las que se le prohibe "toda relación, trato o negociación, por importante que sea, con los enemigos de nuestro adorado Fernando VII. Les ha declarado el reino guerra eterna, que solo terminará por su restitución al trono, libre de toda dependencia de estos, i la tranquila posesión de sus dominios" 2 . En el mismo sentido, de sumo interés es el oficio redactado por Manuel de Salas a nombre del primer Congreso Nacional en respuesta al oficio del virrey con la consulta del Consejo de Regencia a raíz del establecimiento de una junta de gobierno en Chile. La Regencia encargó al virrey actuar con prudencia en aras de fomentar el amor y la obediencia al soberano y cuidar los vínculos de unión con la metrópoli. La regencia hizo presente que ella no se opondría a la junta si ella se dedica a conservar el orden y la tranquilidad

\footnotetext{
${ }^{57}$ Chiaramonte, Carlos, Conceptos y lenguajes políticos en el mundo iberomaericano, en Revista de Estudios Políticos, 140 (Madrid, 2008), p. 24.

${ }^{58}$ Ibíd., p. 25.

${ }^{59}$ Ibíd., p. 25.

${ }^{60}$ Hobsbawn, Eric, Nationen und Nationalismus. Mythos und Realität seit 1780 (Frankfurt/ Main, Campus, 2004), p. 89.

${ }^{61}$ Ibíd., pp. 25-30. Hobsbawn hace en este punto un estudio acerca de la evolución de ese vocablo en castellano.

${ }^{62}$ Sesiones de los Cuerpos Legislativos, I, p 155.
} 
del reino y si los miembros de esta son personas virtuosas ${ }^{63}$. Salas partió informando que las nuevas autoridades chilenas estaban al tanto de la participación de dos vecinos de Santiago en las Cortes de Cádiz ${ }^{64}$. Luego señaló que la Junta de Gobierno suponía que la regencia estaba al tanto del movimiento juntista chileno por medio de la correspondencia con el Marqués de Casa Irujo, embajador hispano en Brasil, pues la ruta de navegación entre Río de Janeiro y España no estaba bloqueada por los franceses. Sin embargo, considera que la oportunidad es única para manifestar que el movimiento juntista chileno y la regencia compartían sentimientos y objetivos. Salas justificó el movimiento juntista en la escasez de noticias provenientes desde España y en los sucesos de Aranjuez y Bayona, en rumores acerca de la regencia de Murat, en el vertiginoso acontecer de los hechos y en un sinfin de noticias contradictorias ${ }^{65}$. Esos fueron los motivos para optar por el sistema de juntas, pues era el mismo que se empleaba en la península. Luego reitera que el movimiento juntista se inspiró en el catolicismo y la monarquía ${ }^{66}$. Salas declara que esta "debe mantener a los reinos fieles y sumisos a Fernando VII $i$ las lejitimas autoridades que en su ausencia gobiernan sus dominios" ${ }^{67}$. Al mismo tiempo, excusa a las autoridades chilenas de no haber mandado representantes ni remesas a Cádiz en el hecho que el movimiento juntista había hecho todo para cumplir con el objetivo indicado ${ }^{68}$. Por esto, el Congreso Nacional se permitió criticar en ese oficio la inoperancia de las autoridades peninsulares frente a la ocupación que ejércitos brasileños hacían de territorios pertenecientes a la Corona hispana ${ }^{69}$. Tomando ese hecho como prueba de la necesidad que tenían los americanos de fortalecer su sistema de gobierno, termina el oficio con la solicitud a la regencia de facilitar los acuerdos con otras provincias americanas a fin de coordinar la defensa de estos reinos ${ }^{70}$. Tal oficio y la anterior instrucción va en la dirección manifestada en la "Declaración de los derechos del pueblo de Chile", tendiente a fortalecer los lazos con otros reinos americanos, manteniendo como lineamiento político la unidad en torno al monarca.

VIII. ACta de acuerdo del Senado y la Junta de Gobierno del 19 de abril DE 1814 Y OTROS ANTECEDENTES MENORES

Como último texto no constitucional es necesario recordar el acta de abril de 1814, por medio de la cual el Senado y la junta de gobierno, repudiaron el actuar de José Miguel Carrera ${ }^{71}$. En ella se reivindica el hecho de que la junta de gobierno de septiembre de 1810 fue aprobada por la Regencia, habiéndosele

\footnotetext{
${ }^{63}$ Ibíd., p. 169.

${ }^{64}$ Ibíd., p. 169.

${ }^{65}$ Ibíd., p. 170.

${ }^{66}$ Ibíd., p. 171.

${ }^{67}$ Ibíd., p. 171.

${ }^{68}$ Ibíd., p. 171.

${ }^{69}$ Ibíd., p. 172.

${ }^{70}$ Ibíd., p. 172.

${ }^{71}$ Ibíd., pp. 338-339.
} 
remitido incluso las actas de su instalación. Agregan que el Congreso juró lealtad a Fernando VII, "mandando a su nombre cuantos títulos i órdenes se espidieron, sin que jamás se intentase ser independientes del rei de España libre, ni faltar al juramento de fidelidad'72. Luego añadió que las intenciones de Carrera y su golpe de estado de 15 de noviembre de 1811 no representaban al pueblo, a las autoridades ni a la prensa. Los Carrera torcieron todos los planes y arguyeron una independencia "que no pudieron proclamar solemnemente por no estar seguros de la voluntad jeneral 73 . Con su política, los Carrera solo provocaron anarquía y desorden, lo que motivó al virrey del Perú a intervenir. Es así como ante tal caos, ambos organismos decidieron nombrar a un gobernador con el título de supremo, por recaer en él la omnímoda facultad que detentó la primera junta el 18 de septiembre de 1810. El director supremo representaba un gobierno análogo a las ideas de la monarquía, con el fin de restituir todo al estado en que se encontraba hasta el 2 de diciembre de $1811^{74}$. Obviamente en este último escrito queda la duda acerca de la conveniencia y oportunidad de esa declaración. Las milicias patriotas carecían de adecuada preparación y no eran un factor disuasivo. Sin embargo, la veracidad de esa declaración, en cuanto a las críticas a Carrera, puede ser avalada por la corta vida que tuvo el primer Congreso Nacional y por la actitud violenta, autoritaria y caudillesca de los Carrera, que les granjeó un sinnúmero de enemigos.

Sin embargo, hay antecedentes que dan fe que las autoridades gobernaron a nombre de Fernando VII. Tal es el caso de una de las reforma que se promulgó en ese período, y que dispuso que la autoridad gobernaba en nombre de él y que en dicha calidad establecía un impuesto de correo - de $1 / 2$ real por carta-, independientemente de su peso o volumen. En ese caso el título que declararon tanto la Junta de Gobierno como el Congreso en el bando respectivo fue " $a$ nombre de Fernando VIr'75. Un caso similar sucedió en medio del debate sobre cementerios y la prohibición de enterrar los cadáveres en las iglesias. En ese caso, uno de los principales impulsores de esa reforma, el diputado Juan Pablo Fretes, fundamentó la necesidad de una reforma en el incumplimiento de una circular de Carlos IV de $1805^{76}$.

\section{Elementos monárquicos en los TEXTOS CONSTITUCiOnales DE LA Patria Vieja}

Hasta ahora se han analizado aspectos jurídicos relevantes, aunque no de primer orden. Al aceptarse la constitución escrita como nuevo medio en que se plasmarán el alcance y los límites del poder estatal, necesario es analizar el tenor literal de los documentos que revisten un carácter constitucional.

\footnotetext{
${ }^{72}$ Ibíd., p. 338.

${ }^{73}$ Ibíd., p. 338.

${ }^{74}$ Ibíd., p. 338.

${ }^{75}$ Ibíd., pp. 108-109.

${ }^{76}$ Ibíd., pp. 145-146.
} 


\section{El Reglamento para el Arreglo de la Autoridad Ejecutiva Provisoria}

Los especialistas están de acuerdo en que éste es el primer documento de la historia constitucional chilena. Como su mismo nombre lo dice, su carácter es transitorio. Fue dictado por un Congreso Nacional, el primero, que duró unos pocos meses, pues fue intervenido por la fuerza a poco de empezar a funcionar. En consecuencia, varias de sus disposiciones quedaron obsoletas, pues se referían a las funciones del legislativo. Si bien su objetivo fue promover el principio de la separación de los poderes del Estado, en los hechos es un documento que deja incólume la organización monárquica. El rol, las funciones y atribuciones que tenía el monarca pasan a ser ocupadas por el Congreso Nacional. Como ya se vio en el análisis de los discursos del acto de instalación de este organismo, a falta de monarca el poder había vuelto a su titular: el pueblo. El pueblo ha elegido un Congreso y con ello ha cambiado el organismo que ejerce la soberanía. Tal situación choca con un sistema de gobierno y un ordenamiento jurídico en que casi todos los órganos representan al monarca y derivan su legitimidad de él. Cambia el órgano que ejerce la soberanía, mas no el ordenamiento jurídico. A contrapelo, el Congreso es una institución nueva en América y Chile.

Lo que hace este reglamento es reconocer que el Congreso -órgano poderosoha llenado el vacío de poder originado por la crisis de la monarquía en España. Así lo refleja su articulado. Su preámbulo parte con una alusión al "Congreso representativo del reino de Chile". Esta frase alude no solo a que Chile es un reino, sino que dicha corporación es la autoridad soberana de éste. Como ya se dijo, este reglamento reconoce expresamente su carácter provisorio, mientras se espera la solución de la crisis de la monarquía. Es así como el art. 6 dispone que toda provisión del ejecutivo se mande como terna al legislativo, para revisar la juricididad de la provisión o el nombramiento, dándose a nombre del rey libre. Se reconoce una situación excepcional, pero no se ha quebrado el principio de legitimidad monárquico, pues las órdenes siguen emitiéndose en su nombre.

$\mathrm{El}$ art. 1 dispone que "El congreso es el único depositario de la voluntad del reino, conoce del cumplimiento o infracción general de la ley". Esta norma ratifica la idea esbozada en el preámbulo de que el pueblo, en ausencia del monarca, es el único titular de la soberanía. La función acá asumida era propia de la Real Audiencia, del Consejo de Indias, del gobernador y de toda la administración indiana. Todos esos órganos la ejercían a nombre del rey. Garantizar el Estado de derecho y el cumplimiento de la legislación vigente es una versión moderna de la obligación del monarca de mantener a sus súbditos en paz y justicia. Quien detenta la soberanía está obligado a garantizar la observancia y el funcionamiento del ordenamiento jurídico, lo que incluía derechos y regalías. La innovación en este artículo es, en consecuencia, de forma y no de fondo.

En el mismo sentido está redactado el art. 3, al establecer que al Congreso le corresponde la representación internacional del Estado. No existe función más propia de la soberanía que el manejo de las relaciones exteriores. Ellas correspondían al monarca; ahora, al Congreso. Por la misma razón, la "apertura de la correspondencia” con otros Estados es atribución suya. Esta disposición prohíbe al Ejecutivo, a contrario sensu, abrir esa correspondencia. Por su parte, el art. 4 establece que al Congreso le corresponde el mando de las armas. Dicha función 
recaía en el gobernador y, posteriormente, en el capitán general, ambos representantes del rey, a quien le correspondía el mando de las tropas en el reino de Chile. Ahora esa función pasa a su reemplazante, como vimos. El artículo siguiente prescribe que la autoridad ejecutiva provisoria no podía disponer de estas fuerzas sin autorización del Congreso.

El derecho indiano contemplaba mecanismos para impugnar la juridicidad de las normas. Tales recursos podían llegar hasta conocimiento del rey. Ahora, el art. 7 establece que es el Congreso el órgano competetente para examinar la juridicidad de las normas de la autoridad ejecutiva. Lo mismo ocurre con la facultad de crear y suprimir empleos, aumentar o aminorar dotaciones (art. 8). Asimismo, las causas de los ramos de gobierno, hacienda y guerra serían conocidas por la autoridad ejecutiva, y en segunda instancia por una junta. En los organismos que la componen destaca la terminología indiana: contador mayor, ministro de Real Hacienda, subdecano de tribunal de justicia y auditor de guerra (art. 10). En materia de jurisdicción, se establece que la "ejecución de penas capitales falladas por cualquier poder o juzgado del reino requerirá permiso del Congreso" (art 12).

De los 19 artículos de este reglamento se concluye que, contrario a su encabezado, este reglamento reguló muy poco la autoridad ejecutiva y en su lugar entregó al congreso las funciones que le correspondían al monarca. No hay división de los poderes del Estado, sino una ratificación del ordenamiento jurídico indiano, con el reemplazo del monarca por el congreso. El rey es mencionado solo en el Art. 6, al prescribir que las decisiones del ejecutivo eran en nombre del rey. Ese punto es interesante. No se descarta la institución monárquica, pero si se acota a una débil autoridad ejecutiva. Este reglamento no muestra intención de derogar la monarquía. Fue hecho para dilucidar las dudas por la falta de monarca. Es una pauta orientadora para que el sistema jurídico pueda seguir funcionando. La forma de gobierno regulada en este reglamento es una monarquía muy sui generis, pues el congreso asume todas las facultades propias del rey, y reconoce para ello como fuente de legitimidad al pueblo.

\section{El Reglamento Constitucional Provisorio de 1812}

Si bien la promulgación de este reglamento es producto de una decisión del primer Congreso Nacional, pareciera que la comisión encargada de su redacción nunca se reunió ${ }^{77}$. Es más, la aparente inactividad de esta comisión fue uno de los argumentos que presentaron José Miguel Carrera y Manuel Rodríguez para justificar la disolución de aquella ${ }^{78}$. De ahí que, no sin razón, la historiografía ha ligado este reglamento a la figura de José Miguel Carrera. Tal afirmación se basa en el hecho de que el reglamento en comento habría sido redactado por un grupúsculo

77 VARAs VelásQUEZ, Miguel, El reglamento constitucional de 1812. Nuevos documentos en Revista Chilena de Historia y Geografía, 18 (Santiago, 1915), p. 107.

${ }^{78}$ Ese manifiesto respecto de la constitución dice en uno de sus párrafos: "[... ] teniendola desde antes hech a por los viejos de la monarquía olvidaron absolutamente su reforma o reprobación tan necesaria a nuestro decoro". MARTÍNEZ, Melchor, Memoria histórica sobre la revolución de Chile desde el cautiverio de Fernando VII hasta 1814. Introducción biográfica de Guillermo Feliú Cruz (Santiago, Ediciones Biblioteca Nacional, 1964), II, p. 4. 
afín a Carrera ${ }^{79}$ o por Agustín Vial Santelices ${ }^{80}$. En opinión de Varas Velásquez, sus bases están en el Congreso de 1811 y en el convenio entre las provincias de Concepción y Santiago, de 13 de enero de $1812^{81}$. Su finalidad fue garantizar la estabilidad en la relación entre las provincias y evitar posibles abusos de poder. Esa interpretación es muy plausible, pues los equilibrios políticos entre los distintos bandos estaban resquebrajados y los grupos patriotas de Concepción y Santiago se recelaban mutuamente ${ }^{82}$. Aparte de ello, aunque ese reglamento hubiere sido solo producto del arbitrio de Carrera y su círculo más estrecho, no está de más recordar que las normas adquieren vida propia distinta de las intenciones de sus redactores y no pocas veces, éstos redactan las normas de manera ambigua, a fin de que admitan más de una interpretación. De los antecedentes analizados en este artículo no queda claro que el sentir de Carrera representase la voluntad general. Decisiva ha sido la interpretación de fray Melchor Martínez a la hora de entender que este reglamento fue una declaración de independencia soterrada ${ }^{83}$.

Sin embargo, hay una serie de elementos que permiten ver esas normas desde otra perspectiva: la de una monarquía, o mejor dicho, una monarquía en que el poder está distribuido de otra forma entre el pueblo y el monarca. En ese sentido, el preámbulo alude a la "facultad de los pueblos de regirse por sí o por sus representantes, como al sagrado asilo de su seguridad”. Luego habla de que Chile también posee ese derecho. Del mismo modo, el preámbulo habla del país como un reino.

Este reglamento cuenta con 27 artículos que se reparten en el aspecto orgánico y de derechos fundamentales. En materia orgánica regula la monarquía, el pueblo, el Senado, la Iglesia y el Cabildo. En materia de derechos, recepcionó la seguridad de las personas, casas y papeles, el habeas corpus, el principio del debido proceso, la libertad de imprenta y la individual. Este reglamento parte reconociendo que la "Religión católica apostólica" es y será siempre la de Chile. Aunque se extraña el calificativo de $\mathrm{r}$ o $\mathrm{m}$ a n a ${ }^{84}$, la elevación de esta institución a nivel constitucional ya representa una línea de continuidad con el derecho indiano. Es la ratificación constitucional del carácter ético-religioso del estado indiano.

$\mathrm{El}$ art. 2 dispone que el pueblo hará una constitución por medio de sus

${ }^{79}$ Dicho grupo fue integrado por Francisco Antonio Pérez, Jaime Zudañez, Manuel de Salas, Hipólito Villegas, Francisco de la Lastra y Camilo Henríquez. Carrasco Delgado, Sergio, cit. (n. 6), p. 35.

${ }^{80}$ Varas, Velásquez, Miguel, cit. (n. 77), p. 109.

${ }^{81}$ Convenio desarrollado en MarTínez, Melchor, cit. (n. 78), pp. 57-59.

${ }^{82}$ Ibíd., p. 48. Prueba de ello es el ya mencionado incidente por el aumento de la representación de Santiago, que motivó una declaración del cabildo penquista, cuyo noveno numerando declaraba que cualquier intento de separación o independencia de las provincias del reino sería considerado delito de Lesa Nación y Lesa Sociedad.

${ }^{83}$ Ibíd., p. 102.

${ }^{84}$ Dicha omisión ha dado lugar a muchas especulaciones. Informa Sergio Carrasco que algunos autores la han entendido como una muestra de exagerado nacionalismo, inspirado en el patronato eclesiástico. Otros piensan que fue un intento de asegurar la independencia en materia spiritual mientras otros creen que fue una idea del cónsul estadounidense Poinsett de asegurar a los norteamericanos la libertad de culto. Otros sostienen que solamente fue un error de imprenta. Carrasco Delgado, Sergio, cit. (n. 6), p. 35. 
representantes. Esto no significa necesariamente un rechazo a la monarquía. Se puede entender como el establecimiento de otro modelo de monarquía, con una nueva distribución del poder, en el marco del descontento general que dejaron las políticas de Carlos IV, acorde con las opiniones manifestadas por Juan Antonio Ovalle y Martínez de Rozas en el acto de instalación del primer Congreso Nacional. Ese artículo es más bien un reflejo de lo que estaba ocurriendo en Cádiz. El art. 3 establece que el rey es Fernando VII, que aceptará esta constitución del mismo modo que la de la península. Dicha norma puede ser entendida como un reconocimiento del interés en continuar siendo una monarquía. Son las mismas ideas que están presentes en Cádiz y a la vez, poniendo de relieve que Chile, al igual que Espana, es parte de una corona, cuyo vínculo es el monarca. Esta norma también admite una lectura como un reconocimiento del carácter de bienes de realengo que tenían los reinos americanos. Eso significa que Chile es libre de darse una constitución, más allá de lo que ocurre en otros reinos de la corona. Su vínculo se da por medio del monarca, no estando supeditados a España u otro reino americano. Además, ese artículo ratifica la idea de que en ausencia del monarca gobierna el pueblo, reiterando la idea básica del reglamento anterior. La innovación es la constitucion escrita. Se parte de la base de que en este nuevo pacto habrá una constitucion escrita, tanto en Chile como en la Península Ibérica.

El establecimiento de una junta superior que gobierna el país a nombre del monarca constituye un reconocimiento a la crisis de la monarquía. Este artículo de por sí representa un retroceso para el Congreso, pues la "junta superior gubernativa” estará a cargo de las relaciones exteriores y del regimen interior. Comparado con el Reglamento para la Autoridad Ejecutiva Provisoria, en esta constitución hay una distribución más equilibrada del poder. No se aprecia un órgano que reúna muchas tareas y facultades, como es el caso del Congreso en el documento de 1811. El monarca no está subrogado por un solo órgano. La junta superior gubernativa detenta competencias que eran del congreso y recibe el trato de "Excelencia", propio del monarca. Las atribuciones del ejecutivo no estaban determinadas. Al parecer eran todas las que no se le habían conferido al Senado.

El art. 5, tradicionalmente entendido como una declaración de independencia, dice que ningún decreto, providencia u orden que emane de cualquier autoridad o tribunales de fuera del territorio de Chile, tendrá efecto alguno. Efectivamente lo que hace este artículo es recalcar que Chile como reino tiene un vínculo de unión con otros reinos americanos y peninsulares a través del rey. Éste no está y ese vínculo con los otros estados miembros de la corona se ha roto pues el poder regio esta en receso. El poder ha vuelto a los pueblos, como lo demuestra la experiencia gaditana. Lo mismo ocurre con los órganos que conforman el aparato administrativo y judicial de Indias. Su carácter supranacional se basa en que representan al rey, pero al no estar éste y no haber certeza sobre su futuro, estos órganos carecen de legitimidad. Podrían inclusive estar vacantes, pues sus titulares renunciaban, morían, o su período de ejercicio expiraba. Surgía la pregunta de quien era el competente para designar al sucesor. Por ende, sus resoluciones no podían tener efecto en Chile. El art. 5 debe interpretarse en concordancia con el art. 3. Ellos reflejan el mismo espíritu del intercambio epistolar entre la regencia y el Congreso Nacional, representado por Manuel de Salas. Lo que hay es voluntad 
de seguir siendo parte de la corona, que fue vista por la regencia con buenos ojos. $\mathrm{El}$ art. 5 sólo representa la idea de que hay reinos distintos, una sola corona y un solo monarca. Apoya esta idea lo dispuesto en la última frase del art. 27, que manda a informar de esa constitución a España y América. Una declaración de independencia no habría hecho eso, o al menos no en esos términos. Más coherente resulta la idea de ratificar la autonomía dentro de la Corona. Se comparte al monarca, pero cada reino es autónomo para darse sus propias normas. También apoya esta interpretación la frase del art. 24, que prescribe que "el español es nuestro hermano". Los artículos 24 y 27 coinciden con los planteamientos de la Declaración de los Derechos del Pueblo de Chile. El art. 6, por su parte, reitera la concepción de soberanía popular. Ella se expresa en la Constitución, y los gobernantes deben obedecer esa voluntad.

El Senado merece un párrafo aparte. Este vocablo tiene una larga historia en el derecho público. El nombre data de la Roma clásica, aludiendo a la asamblea de gente mayor, dotada de experiencia y moderación y revestida, por tanto, de auctoritas, esto es, el saber socialmente reconocido. Los hombres cultos del siglo XVIII manejaban la cultura clásica, y más de un publicista resaltó la necesidad de contar con un Senado para gobernar ${ }^{85}$ pero solo la constitución norteamericana lo consagró explícitamente, como órgano cuyo fin era mantener los equilibrios de poder entre los distintos Estados miembros. Cada uno de ellos contaba con dos escaños en la corporación. El diseño institucional de éste lo llevó a diferenciarse de la Cámara Baja, ganando prestigio por su moderación ${ }^{86}$. Con probabilidad, el Senado estadounidense fue tomado parcialmente como modelo para regular el que aparecía en este reglamento constitucional. Prueba de ello es su composición de 7 escaños: dos por la provincia de Coquimbo, dos por la de Concepción y tres por la de Santiago ${ }^{87}$, tratando de esta manera de apaciguar ánimos en Concepción tras la disolución del Congreso. Sin embargo, como señala Gonzalo Vial, la influencia norteamericana llegaría solo hasta la representación de las respectivas provincias y a su facultad de dirimir contiendas entre éstas. Este Senado carecía de la capacidad de actuar como cámara moderadora pues no había otra asamblea que cumpliese el papel de cámara política ${ }^{88}$. En el resto, no tiene una función propiamente legislativa sino consultiva ${ }^{89}$, pues no iniciaba ni modificaba los proyectos que le presentaban, limitándose a emitir una opinión. Sus bases son

${ }^{85}$ Montesquieu afirma: "El pueblo tiene el poder soberano de hacer por sí mismo todo lo que pueda hacer bien. Lo demás es preciso que lo haga por medio de sus ministros [...] necesita el pueblo, lo mismo que los monarcas y aún más que ellos, ser dirigido por un consejo o senado mas si ha de tener confianza en él, fuerza es que elija a sus miembros, ya directamente, como en Atenas, ya por medio de algún magistrado, según se practicaba en Roma" MONTESQUIEU, Barón de Charles Lois de Secondant, El espiritu de las leyes de Montesquieu (traducido al castellano por Siro García de Mazo) (Madrid, Librería general de Victoriano Suárez, 1906), I, p. 22.

${ }^{86}$ Vial Correa, Gonzalo, Historia del Senado de Chile (Santiago, Editorial Andrés Bello, 1995), p. 8.

${ }^{87}$ Sin embargo, todos los miembros eran santiaguinos.

${ }^{88}$ Vial Correa, Gonzalo, cit. (n. 86), p. 10.

${ }^{89}$ Theoduloz VÁsquez, Nahum, Estudio del Senado chileno: evolución histórica, composición, funciones y atribuciones (Santiago, Imprenta de Chile, 1950), p. 15. 
las mismas que las del documento de aveniencia entre las provincias de enero de 1812, celebrado entre representantes de Carrera y Martínez de Rozas. Fue una manera de equiparar el poder entre las tres provincias, y en su aspecto orgánico, tenía que cumplir el rol de darles igual representación. Debía emitir un dictamen sobre los negocios graves de la nación y poseía facultades jurisdiccionales como ser el tribunal competente para conocer los juicios de residencia y recursos de amparo a presos políticos. Su labor fue importante en materias como la libertad de imprenta ${ }^{90}$, pueblos de indios y propiedad indígena ${ }^{91}$, nombramiento de miembros de la judicatura ${ }^{92}$, reformas a la justicia militar ${ }^{93}$ y derogación de los derechos parroquiales para efectos de otorgar los sacramentos ${ }^{94}$, entre otros. El rol que jugó esa corporación en esas discusiones no fue propiamente legislativo, sino que de asesoría y opinión. La emisión de un dictamen tiene mayor relación con una consulta acerca de la conveniencia de la promulgación de una norma que con su aprobación o rechazo. El art. 7 establece la obligación de pedir un dictamen del Senado, pero eso no quiere decir que este fuese obligatorio para el gobierno. El acto trascendente era solicitar la opinión, no guiarse por ella. Asumió, entonces, una serie de funciones que le correspondían hasta abril de 1811 a la Real Audiencia, como ser el tribunal competente para conocer los juicios de residencia, participar del nombramiento de jueces, observar la situación de los indígenas, adjudicar mercedes de tierra y aguas y regular el real patronato, lo que también incluía revisar los cobros que los párrocos hacían a la feligresía. ${ }^{95}$ En fin, era más una nueva Real Audiencia que propiamente una cámara legislativa.

El proceso de redacción de este reglamento también da algunas luces acerca de su sistema de gobierno. A este respecto, los antecedentes proporcionados por Varas Velásquez son muy útiles. El borrador del reglamento mereció reparos por parte del Cabildo Eclesiástico de Santiago, que formuló observaciones y críticas a los artículos 1 y 5 del primer borrador. El texto original del art. 5 versaba: "en ningún evento se reconocerán las Cortes, Regencia o cualquier otro gobierno que se instituya en Espana, mientras no se le restituya a su trono a Fernando VII y si se llega a este caso y el de que no se declare la independencia, el reino entrará en negociaciones y lo sostendrá para obtener la libertad de comercio y de tener manufacturas para que la provisión de los empleos se haga a los naturales del pais y para que el gobierno tomando de otro forma no quede como en el pasado expuesto a los horrores del despotismo y la arbitrariedad'96. Frente a ese proyecto manifestó sus reparos pues, en primer lugar, consideraba que el contenido de esa norma era contradictorio con el juramento prestado en la instalación del Congreso. En segundo lugar, el

\footnotetext{
${ }^{90}$ Sesiones de los Cuerpos Legislativos, I, pp. 282-283.

${ }^{91}$ Ibíd., p. 285-286.

${ }^{92}$ Ibíd., p. 323.

${ }^{93}$ Ibíd., p. 287.

${ }^{94}$ Ibíd., p. 278-279.

${ }_{95}$ Para esto se ha revisado la real cédula $\mathrm{N}^{\circ} 190$, que estatuyó la Real Audiencia de Santiago. En LizAnA MARTínez, Elías, Colección de documentos históricos recopilados del archivo del arzobispado de Santiago (Santiago, Imprenta San José, 1919-1921), II, pp. 316-339.

${ }^{96}$ VARAS VelásQUeZ, Miguel, cit. (n. 77), pp. 124-125.
} 
cabildo manifestaba su interés en el reconocimiento de los Cortes de Cádiz como órgano detentador de la soberanía y representante de la monarquía. Su opinión se basaba en la participación que la Corte le había dado a los americanos y en el hecho de estar aquellas cortes redactando una constitución. Llamativa es la idea de que el reconocimiento a las Cortes y a la Regencia se supedite a la restitución de Fernando VII.

Sobre el artículo 5, el Cabildo Eclesiástico lo consideró desde el comienzo un problema, pues el catolicismo reconocía -y reconoce- como máxima autoridad al Romano Pontífice. En el caso chileno, además, los obispados de Concepción y Santiago eran sufragáneos del obispado metropolitano de Lima. Dicha norma representaba también una violación de los derechos de la Iglesia chilena, pues aparte de las dos mencionadas autoridades, quedaban catalogadas como extranjeras el comisario general de la Santa Cruzada y el tribunal de la Inquisición. Es decir, la Iglesia chilena reconocía algunas autoridades fuera del territorio del reino, con poder de jurisdicción y la facultad de dictar normas, cuyas resoluciones y normas, acorde al art. 5, se verían privadas de todo efecto jurídico: el Papa, el nuncio legado, el comisario general de la Santa Cruzada, el obispo metropolitano y el Tribunal de la Inquisición ${ }^{97}$.

Otro elemento histórico útil en este reglamento es la convención entre Santiago y Concepción ${ }^{98}$, provincia esta última que entendió que por la disolución del Congreso había perdido toda influencia y capacidad de decisión en el gobierno del reino. Previo movimiento de tropas, se llegó a un acuerdo de 23 puntos, de los cuales son de relevancia para esta investigación, primero, la declaración de que "la autoridad suprema reside en el pueblo chileno". Esa declaración admite una lectura moderna y otra vinculada al pensamiento escolástico hispano, con eco en el mundo indiano del siglo XVIII. En segundo lugar, con una finalidad exclusivamente política, la abierta manifestación de interés por "la permanencia, perpetuidad y progresos del sistema adoptado, y causa general de América". Tal declaración admite varias interpretaciones. Desde una que legitima el movimiento independentista, hasta otra que ratifica el interés por reformas a la monarquía indiana en su conjunto. Creemos que a favor de esta última interpretación juega la Declaración de los derechos del pueblo de Chile. Respecto al poder legislativo, el punto tercero afirma: "quedan suspendidas las funciones del Congreso hasta que llegue el caso en que sea preciso formar una constitución permanente, lo que se verificará ocupada que sea España por los franceses o por si justos y necesarios motivos fuese indispensable declarar antes la independencia". Tal situación puede entenderse como una pervivencia de la monarquía indiana sujeta a esas dos condiciones. La primera suponía que España lograría expulsar a los invasores y que el rey volvería a gobernar. El congreso o parlamento era una institución nueva en América y en Chile, que asumiría el rol de soberano si no cabía otra posibilidad.

Pero más importante que eso es la ratificación del interés por redactar una constitución. Es una muestra del interés que generaba la constitución escrita en

${ }^{97}$ Carta de José Santiago Rodríguez, transcrita en Varas Velasquez. Miguel, cit. (n. 77), pp. 130-131.

${ }_{98}$ Martínez, Melchor, cit. (n. 78), pp. 57-59. 
esos grupos, y de como esta nueva acepción de la palabra c o n s t i t u c i ó n había entrado en la idiosincracia política y jurídica chilena. Importante es también considerar en qué casos se redactaría una constitución permanente. Tales serían la declaración de la independencia o la ocupación de España por los franceses. En otras palabras, solo en caso de no existir ni la más remota posibilidad de un retorno de Fernando VII. La puerta a la monarquía o, mejor dicho, a una nueva monarquía, quedaba más que entreabierta. El interés por redactar una constitución se da en el acto de avenimiento entre Santiago y Concepción de la misma manera que en las Cortes de Cádiz: la constitución escrita no es rechazo a la monarquía sino su reforma.

El décimoprimer numeral del acta se asemeja a la polémica version original del art. 5 del reglamento constitucional. Su tenor literal prescribe que "en ningún evento se reconoceran las Cortes, la regencia o cualquier otro gobierno que se instituya en España, ni se admitirán los empleados que de ella se manden, mientras no se le restituya en el trono al Rey Fernando VII, y si llega a este caso y el de que no se declare la independencia, el reino entrará en negociaciones, y lo sostendrá para obtener la libertad de comercio y de tener manufacturas para que la provisión de los empleos se haga en los naturales del país y para que el gobierno tomando otra forma no quede como en lo pasado expuesto a los horrores del despotismo y la arbitrariedad'. Este numeral es complejo desde un punto de vista jurídico. En sí implica un rechazo a la política borbónica de transformar la Corona en un imperio. Se puede entender que es una reivindicación del carácter de bienes de realengo que poseen las Indias 99 . A su vez, es una reivindicación de la autonomía política del reino frente a la península. Del mismo modo, busca acabar con una de las peculiaridades de la monarquía indiana: el hecho de que parte de sus autoridades eran oriundas de Castilla. Representa la reivindicación del derecho de acceder a los cargos públicos por parte de los nacidos en Chile. Dicha petición está en sintonía con las obras de filosofía política surgidas en América en el siglo XVII. Por su parte, la ideología ilustrada queda de manifiesto en el interés por la libertad de comercio.

Aparte de ello, el principal influjo monárquico en este punto es el interés por seguir siendo, en la medida de lo posible, parte de la Corona. Del tenor literal de este numeral y del anterior no es posible concluir con seguridad si hay un interés en que la Corona sea una unión personal o real ${ }^{100}$. Al parecer, conservar la unión real no era un horizonte compartido por todos los participantes de esa negociación. Sin embargo, la "Declaración de los Derechos del Pueblo de Chile" parece apuntar en el sentido de continuar en una unión real, pero ésta vez contando con una constitución escrita que emanase del pueblo.

Por último, reviste especial interés para esta investigación el numeral duodécimo, que fija los casos en que se declararía la independencia. Tal situación se verificaría en caso de que los franceses ocupasen toda España, aun cuando Cádiz lograse mantener su independencia. Pero a reglón seguido afirma que mientras

\footnotetext{
${ }^{99} \mathrm{Al}$ respecto, véase el libro de Zorraquín Becú, arriba mencionado.

${ }^{100}$ Somos de esta opinión pues a diferencia de lo dispuesto en la Declaración de los Derechos del Pueblo de Chile, acá no se habla de instituciones compartidas con otros reinos integrantes de la Corona indiana.
} 
quedase un hombre vivo, no se sometería a potencia extranjera ni a otra autoridad que a Fernando VII y si este no se restableciere, a ninguno. Este numeral posee varios aspectos propios de una transacción entre distintos intereses. Pareciera ser incluso contradictorio. Pensamos que ceñirse a la figura de Fernando VII es propio de una manera de entender la monarquía típica de los Austria. En ese momento claramente se podía entrever la posibilidad de que, o Fernando VII no regresase, o que las Cortes, en acuerdo con la realeza optasen por darle a otra persona el cargo de rey. Mal que mal, un sector de la sociedad española había aceptado a José Bonaparte, validando de esa forma la ruptura del principio de no usurpación del trono. Claramente, una decisión así pasaba por las Cortes extraordinarias de Cádiz, en las que Chile no contaba con representación oficial. Al considerarse un bien de realengo y no una monarquía de carácter nacional, es legítimo entender que no se reconozca ninguna potestad de Cádiz en ese aspecto, pues Cádiz representa a otros pueblos, no al del reino de Chile. Es una ratificación de la idea de unión por medio del rey. El rey es elemento aglutinador de los distintos reinos de la Corona.

Esta convención entre Santiago y Concepción no fue aceptada por Carrera. Según Melchor Martínez, la causa fue la negativa a que Martínez de Rozas quedase a su mismo nivel ${ }^{101}$. Dicha rivalidad solo terminó cuando, el 8 de julio de 1812, cinco oficiales del ejército depusieron a la junta de Concepción y mandaron a Martínez de Rozas reo a Santiago ${ }^{102}$. Las consecuencias de esta acción fueron enormes, pues atizó la ya existente desconfianza penquista hacia Santiago y hacia los hermanos Carrera, convenciendo a los realistas del sur de Chile de apoyar la expedición militar mandada por el virrey. Del mismo modo, dicha acción deslegitimó el Reglamento Constitucional de 1812, el que fue entendido como un arbitrio de Carrera, generando dificultades para su juramento en Concepción y Coquimbo.

Como último punto sobre este reglamento es importante indicar que la existencia de esa convención permite una interpretación objetiva deese texto. Esa convención muestra diferencias entre la voluntad de Carrera y el contenido del reglamento.

\section{El Reglamento para el Gobierno Provisorio.}

Este reglamento se promulgó en marzo de 1814, en el marco del conflicto armado con el virrey del Perú y las sucesivas derrotas sufridas por los patriotas en el campo de batalla. Quizás por eso su aporte al desarrollo dogmático del derecho público es escaso. Fue dictado sobre el supuesto de que no hay Congreso, pero se cuenta en cambio con un Senado, cuya naturaleza orgánica queda mejor delimitada que en el Reglamento de 1812. Esta vez se reconoce que su función es consultiva y no legislativa. Los órganos consultivos son propios de regimenes monárquicos, y ciertamente este Senado es una manifestación de ello.

En materia de funciones gubernamentales, el art. 1 concentra el poder ejecutivo en una autoridad unipersonal: el director supremo. De acuerdo a esa norma, dicho

\footnotetext{
${ }^{101}$ Martínez, Melchor, cit. (n. 78), pp. 60 y 72.

${ }^{102}$ Ibíd., p. 77.
} 
nombre de se debía a que detentaba "las absolutas facultades que ha tenido la junta en su instalación de 18 de septiembre de 1810". En otras palabras, se retrotrae hasta el momento en el que por primera vez desde el comienzo de la crisis monárquica, una institución asume que el poder ha vuelto al pueblo pues el rey no lo puede ejercer. Esa norma es un reconocimiento a la teoría del origen del poder vigente en Indias. El poder es detentado por el rey, pero éste proviene del pueblo.

La institución a que nos referimos representa una vuelta al poder constituyente originario, esta vez radicado en un órgano unipersonal ${ }^{103}$. En ese sentido, el art. 2 reconoce que sus facultades son ilimitadas. Las únicas excepciones son los tratados de paz, declaraciones de guerra, nuevos establecimientos de comercio, pechos o contribuciones generales, que deberían ser consultadas y acordadas con el Senado. En este reglamento también hay un símil con la Real Audiencia, en cuanto al ejercicio de la función consultiva. No obstante lo anterior, es poco lo que se puede decir sobre este Senado consultivo, regulado como un anexo del reglamento, dado que solo funcionó hasta el 23 de junio de 1814. Casi no hay antecedentes de su gestión ${ }^{104}$, salvo haber sentado las bases del tratado de Lircay ${ }^{105}$. El establecimiento de la figura del director supremo significaba un retroceso frente a la naciente regulación patria y frente al derecho indiano. Al menos, en el último ordenamiento no había institución con facultades ilimitadas.

El aparataje simbólico que acompañaba al director supremo era muy monárquico. Debía ser tratado de "Excelencia" (art. 3) y le correspondían la escolta y los honores de un capitán general (art. 4). Es inconcuso que esta nueva institución se revistió de las formas del gobernador de la época indiana. Su período sería de 18 meses, prorrogable por acuerdo de la municipalidad y el Senado. Se reconoce que el pueblo es el detentatario original del poder. En caso de enfermedad, muerte $\mathrm{u}$ otro imedimento sería subrogado por el gobernador intendente de la provincia. Es decir, la subrogación del director supremo también recurre y valida la institucionalidad indiana.

El director supremo fue pensado para una situación de emergencia. Se podría definir como un estado de excepción constitucional. Sin embargo, este reglamento estableció un freno a su poder: el juicio de residencia. Este procedimiento tenía la ventaja de ser accesible a cualquiera que se considerase perjudicado con la gestión de su autoridad. Era una institución de larga data en el derecho indiano, bien regulada y por ello una forma efectiva de controlar a los gobernantes. El juez competente debía ser elegido por el Congreso o, de faltar éste, por las corporaciones ${ }^{106}$.

\section{Balance constitucional de la Patria Vieja}

La Patria Vieja terminó con el desastre de Rancagua y la restauración absolutista. Los excesos y la represión con que actuaron los realistas terminaron por

${ }^{103}$ Véase acá el punto anterior referido al acta de acuerdo del Senado y la Junta de Gobierno de 19 de abril de 1814 .

104 Theoduloz Vásquez, Nahum, cit. (n. 89), p. 16.

${ }^{105}$ Vial Correa, Gonzalo, cit. (n. 88), p. 20.

${ }^{106}$ Ese reglamento partía de la base de que al cabo de 18 meses se elegiría un nuevo Congreso. 
deslegitimar al monarca en Chile. Por esa razón, marca no solo un punto de inflexión en la historia de la independencia, sino también en la constitucional. A partir de ese momento se rompen todos los vínculos con Fernando VII, abriéndose otros derroteros.

En lo constitucional puede observarse que en los reglamentos constitucionales del periodo en cuestión hay una fuerte ascendencia del derecho indiano y en todos ellos se recurre a la institucionalidad indiana para establecer un sistema de frenos y contrapesos ${ }^{107}$. Hay poca claridad en cuanto a la recepción e implementación de las nuevas ideas. Se habla del principio de separación de los poderes del Estado, pero se mantiene el sistema de gobierno por ramos, propio del derecho indiano. El reglamento de la autoridad ejecutiva provisoria lo que menos hace es regular a esa autoridad, sino decidir quien ocupará el papel del monarca. Así se concibe un Congreso que en vez de cumplir con las funciones propias del poder legislativo se dedica a hacer las veces de rey, dandole de paso legitimidad a todo el sistema jurídico.

El Reglamento constitucional de 1812 es más complejo de analizar y sistematizar, en parte por la discordancia entre la interpretación histórica mayoritaria y lo que se desprende de un análisis detallado de sus disposiciones y fuentes. $\mathrm{Su}$ art. 5 ha sido sobrevalorado, en desmedro de una serie de antecedentes político y jurídicos posteriores y anteriores a ese reglamento, siendo probablemente los documentos más indicativos de las ideas imperantes y de las transacciones entre carrerinos y otros grupos políticos la "Declaración de los derechos del pueblo de Chile" y el "Acta de aveniencia entre Concepción y Santiago". Ambas contemplan la posibilidad de una independencia, pero es una posibilidad muy remota. Ambos documentos se inclinan más por una monarquía constitucional.

Importante es destacar el rol que juegan las concepciones filosófico-jurídicas de la época de los Austria. El debate filosófico-jurídico, con fundamentos en la Biblia, es una controversia entre las ideas defendidas por la dinastía de los Borbones y las de la época de los Austria. La discusión a favor del llamado a elecciones de un Congreso en Chile no fue diferente del que ocurrió en otras regiones de la monarquía, como Nueva España.

El Senado en los textos de 1812 y 1814 muestra como el primer constitucionalismo chileno no estuvo ajeno al fenómeno europeo de monarquización de las repúblicas y republicanización de las monarquías. El Senado, como se vio, ya fue pensado con ese nombre por Montesquieu y su primer modelo moderno fue el de la constitución norteamericana. Sin embargo, en Chile surge no como parte de un sistema bicameral sino como una manera de soslayar la ausencia de un Congreso. Por ende, se trata de una institución difícil de encuadrar en algún modelo. Una o dos de sus normas parecen tener claramente un carácter federalista, pero el resto se refieren más a un órgano de carácter consultivo que resolutivo. En ese sentido se acomoda más a la Real Audiencia que a un poder legislativo moderno, pues asume muchas de su funciones. En ese sentido, una institución

107 Dougnac Rodríguez, Antonio, El sistema jurídico indiano en el constitucionalismo chileno, cit. (n. 1). 
monárquica fue reemplazada por otra de origen popular pero que cumplía roles propios de una monarquía.

La institución de la representación también exhibe elementos propios del derecho indiano. El Congreso es una novedad como institución. Qué cada persona habilitada pueda ir a votar o firmar a favor de un candidato ya es de por sí una novedad, pero el hecho de que el diputado deba ajustarse solo a lo dispuesto en el mandato no tiene nada de nuevo y era poco compatible con la lógica de un poder legislativo moderno.En ese sentido, Chile no estuvo ajeno al surgimiento de sistemas políticos que son una mezcla de nuevas y viejas instituciones, lo que muchas veces dificultó su comprensión y funcionamiento.

Por último, en Chile se impuso la idea de la constitución escrita. Ella fue entendida en el marco de una concepción del derecho como fenómeno histórico. Sus fundamentos se buscaron en la historia y la tradición. Había interés en hacer cambios, pero no se quería prescindir de aquello que se tenía.

En cuanto a la monocracia, en estos años está en receso. El poder ejecutivo es manejado preferentemente por juntas. Tal situación se debió, probablemente, a que la figura monocrática por antonomasia, el rey, estaba ausente. Solo con ocasión de la guerra se vuelve a una figura monocratica como el director supremo. Llamativo es que el poder ejecutivo en general recibe poca regulación, comparado con otros aspectos de estos reglamentos.

Como último aspecto de este balance, es digno de remarcar que, en el marco de una adaptación monárquica, el poder constituyente reside casi por entero en el pueblo. Resulta paradójico que en un sistema de gobierno de fuertes inclinaciones monárquicas el poder constituyente radique finalmente en el pueblo. La Patria Vieja es un momento de sistemas de gobierno sui generis, que no tiene nada que envidiar a otros modelos muy especiales que en esa época surgieron en otras latitudes ${ }^{108}$. Claramente, este modelo de gobierno no se corresponde con las monarquías constitucionales europeas del siglo XIX, pues ellas reconocían como fuente de legitimidad al monarca.

\section{Conclusión: ¿Monarquía constitucional?}

Con estos antecedentes a la vista, es oportuno cuestionarse la validez de la tesis de la monarquía constitucional. Se trata de una categoría preferentemente europea que describe los gobiernos del siglo XIX en ese continente y no pocos ven su primera manifestación en la Constitución francesa de 1814. Ellas recepcionaron el principio monárquico, de acuerdo al cual la soberanía viene del monarca, y si bien el poder es ejercido acorde lo prescrito en la constitución, es él la única fuente de legitimidad. El monarca detentaba el ejecutivo, tenía iniciativa legal y

\footnotetext{
${ }^{108}$ Piénsese que solo Francia desarrolla en esa época tres modelos constitucionales distintos; además, está el caso de Polonia y el de Suecia, que desarrollaron sistemas intermedios entre la constitución jurisdiccional y el constitucionalismo moderno.
} 
actuaba como juez supremo ${ }^{109}$. La monarquía constitucional, como puede verse, era muy autocrática ${ }^{110}$.

En el mundo hispanoparlante la constitución española de 1837 se corresponde con la monarquía constitucional ${ }^{111}$. Así, Rodríguez de Cepeda define al monarca con las siguientes palabras: "El rey es jefe supremo, representante del Estado, goza de todas las prerrogativas inherentes a su alta y elevada autoridad y necesarias para mantener el orden y en lo esterior la dignidad nacional. Sanciona las leyes y cuida su egecución; vela sobre la recta administración de justicia; dispone de la fuerza armada $y$ dirige las relaciones diplomáticas; mantiene en fin el equilibrio entre los intereses, ideas y pasiones que se agitan y combaten en los cuerpos colegisladores, ora convocándolos, ora suspendiendo sus sesiones, ora disolviendo el congreso de los diputados para consultar de nuevo al cuerpo electoral y conocer por este medio el verdadero estado de la opinion pública" ${ }^{112}$. Teniendo a la vista esta definición, las características del sistema de gobierno de la Patria Vieja no se corresponden con la monarquía constitucional, pues en el caso chileno todo el poder venía en última instancia del pueblo y el monarca era solo un mandatario. El sistema es una pervivencia reformada de la monarquía indiana, pero el rey sólo es fuente legitimadora del poder, primero para suplir el vacío generado por el cautiverio de Fernando VII y luego como el argumento en base al cual el poder ha vuelto al pueblo. El lugar que dejó el rey es ocupado por órganos primero provisorios y luego de e le c c i ó n p o p u l a r, que deben respetar las bases de la monarquía y el catolicismo. Sin embargo, la permanencia en la corona dependía de algunos factores poco ponderables en ese momento.

En otras palabras, se instaura un sistema de gobierno en el que el monarca es factor de unidad, pero en el que él como organismo no posee mayores atribuciones. En cuatro años se evoluciona desde una regencia a un sistema monárquico sui generis, o como postuló Marquardt, de monarquía liberal. Ese modelo se caracterizó por dejar en la cúspide al monarca, como cabeza del ejecutivo, pero intenta modificar el sistema acorde a una lógica republicana y democrática. Lo más interesante de este modelo, hasta ahora poco explorado, es que se concibe como un sistema en el que la soberanía viene del pueblo y en el que el Congreso u otros órganos llevan los destinos politicos del reino, respetando las bases antes indicadas. Se trata de una reforma a la monarquía indiana, con un fuerte acento en la soberanía popular. En defnitiva, en la Patria Vieja el poder constituyente no pasó por el rey.

${ }^{109}$ Müssig, Ulrike, Die europäische Verfassungsdiskussion des 18. Jahrhunderts (Tübingen, Mohr Siebeck, 2008), p. 88.

${ }^{110}$ Marquardt, Bernd, Dos siglos de historia constitucional en América Latina (1810-2010). Historia constitucional comparada (Bogotá, Universidad Nacional de Colombia, 2011), I, p. 34.

${ }^{111}$ Rodríguez de CePEDA, Antonio, Elementos de derecho público español (Madrid, Librería de García, 1842), p. 32.

${ }^{112}$ Ibíd., pp. 32-33. 


\section{BiBLIOGRAFÍA}

Andrades Rivas, Eduardo, El ocaso del Reino (Tesis doctoral Facultad de Derecho de la Universidad Nacional de Educación a Distancia, Madrid, 2019).

Carrasco Delgado, Sergio, Génesis y vigencia de los textos constitucionales chilenos ${ }^{3}$ (1983, Santiago, Editorial Jurídica de Chile, 2002).

Cartes Montory, Armando, “Un gobierno de los pueblos...”. Relaciones provinciales en la Independencia de Chile (Valparaíso, Ediciones Universitarias de Valparaíso, 2014). Ahora como "Un gobierno de los pueblos...": la nación y las provincias en la Independencia de Chile (Santiago, Ediciones Centro de Estudios Bicentenario, 2018).

Cavieres Figueroa, Eduardo, Discursos ilustrados y politicas reales. Los límites de la representación desde la base. Prólogo a "Un gobierno de los pueblos...". Relaciones provinciales en la Independencia de Chile, pp. 13-31.

Chiaramonte, Carlos, Conceptos y lenguajes políticos en el mundo iberomaericano, 17501850, en Revista de Estudios Politicos, 140 (Madrid, 2008), pp. 11-31.

Concha Márquez de la Plata, Sergio, De las juras reales a las juras constitucionales: la continuidad de un ceremonial en Chile, en GuZMÁn Brito, Alejandro (ed.), El derecho de las Indias occidentales y su pervivencia en los derechos patrios de América. Actas del Decimosexto Congreso del Instituto Internacional de Historia del Derecho Indiano (Valparaíso, Ediciones Universitarias de Valparaíso, 2010), II, pp. 941-953.

Diario de Sesiones de las Cortes Generales y Extraordinarias (Madrid, Impr. José A. García, 1870-1871) 15 vols.

Dougnac Rodríguez, Antonio, El Sistema jurídico indiano en el constitucionalismo chileno durante la Patria Vieja (1810- 1814), en REHJ., 22 (Valparaíso, 2000), pp. 225-266.

—Un jurista indiano en la ruta de Hobbes, en RChHD. 17 (Santiago, 1992), pp. 29-55.

GONZÁlez ECHEÑIQUe, Javier, Un estudio de influencias doctrinarias en la Independencia: el concepto de diputado o representante popular. 1810-1828, en Revista Historia, 6 (Santiago, 1967), pp. 127-152.

Guerrero Lira, Cristian, El primer Congreso Nacional de Chile (1811) y sus documentos fundamentales (Santiago, Ediciones Centro de Estudios Bicentenario, 2011).

HeIse GonZÁlez, Julio. Años de formación y aprendizaje politicos: 1810-1833 (Santiago, Editorial Universitaria, 1978).

Hobsbawn, Eric, Nationen und Nationalismus. Mythos und Realität seit 1780 (Frankfurt/ Main, Campus, 2004).

Infante Marín, Javier, Autonomía, Independencia y República en Chile (1810-1828) (Santiago, Ediciones Centro de Estudios Bicentenario, 2014).

Letelier, Valentín (ed.), Sesiones de los Cuerpos Legislativos de la República de Chile. 1811-1848 (Santiago, Imprenta Cervantes, 1886-1908), 37 vols.

Lizana Martínez, Elías, Colección de documentos históricos recopilados del archivo del arzobispado de Santiago (Santiago, Imprenta San José, 1919-1921), 4 vols.

Lorente Sariñena, Marta, El juramento constitucional, en AHDE., 65 (1995), pp. 585-632.

MARQUARDT, Bernd, Dos siglos de historia constitucional en América Latina (1810-2010). Historia constitucional comparada (Bogotá, Universidad Nacional de Colombia, 2011), 2 vols. 
Martínez, Melchor, Memoria histórica sobre la revolución de Chile desde el cautiverio de Fernando VII hasta 1814. Introducción biográfica de Guillermo Feliú Cruz (Santiago, Ediciones Biblioteca Nacional, 1964), 2 vols.

Martiré, Eduardo, Algo más sobre el derecho indiano (entre el ius commune medieval y la modernidad), en AHDE., 73 (Madrid, 2003), pp. 231-264.

Montesquieu, Barón de Charles Lois de Secondant, El espiritu de las leyes de Montesquieu (traducido al castellano por Siro García de Mazo) (Madrid, Librería general de Victoriano Suárez, 1906), 2 vols.

Müssig, Ulrike, Die europäische Verfassungsdiskussion des 18. Jahrhunderts (Tübingen, Mohr Siebeck, 2008).

Palma González, Eric, Estado Constitucional Liberal Católico en Chile (1812-1924): nueva historia

constitucional (Santiago, Orion, 2011).

Peña-Peñaloza, Roberto, Los derechos naturales del hombre en la ideología del siglo XVIII rioplatense, en RChHD., 16 (Santiago, 1990-1991), pp. 193-204.

Pérez Perdomo, Rogelio, Tradicionalismo y modernismo en la filosofía del derecho del siglo XVIII español, en Derecho PUCP. Revista de la Facultad de Derecho, 26 (Lima, 1968), pp. 39-46.

Prodi, Paolo (coord.), Glaube und Eid Glaube und Eid: Treueformeln, Glaubensbekenntnisse und Sozialdisziplinierung zwischen Mittelalter und Neuzeit Der Eid in der europäischen Verfassungsgechichte. Zur Einführung (München, Oldenbourg Verlag, 1993).

Quagioni, Diego, Giuramento e sovranita. Il Giuramento como limite de la sovranita nella Republique di Jean Bodin, en ProDI, Paolo (coord.), Glaube und Eid Glaube und Eid: Treueformeln, Glaubensbekenntnisse und Sozialdisziplinierung zwischen Mittelalter und Neuzeit Der Eid in der europäischen Verfassungsgechichte. Zur Einführung (München, Oldenbourg Verlag, 1993), pp. 97-111.

Rodríguez De CEPEDA, Antonio, Elementos de derecho público español (Madrid, Librería de García, 1842).

Romano, Andrea, Cádiz en Italia. La recepción de la constitución de Cádiz en Italia y la Revolución Piamontesa, en Escudero, José Antonio (ed.), Cortes y Constitución de Cádiz. 200 años (Madrid, Espasa Calpe, 2011), III, pp. 459-472.

Soberanes Fernández, José Luis, El pensamiento constitucional en la Independencia (Ciudad de México, Editorial Porrúa-UNAM, 2012).

Theoduloz VÁsquez, Nahum, Estudio del Senado chileno: evolución histórica, composición, funciones y atribuciones (Santiago, Imprenta de Chile, 1950).

Varas Velásquez, Miguel, El reglamento constitucional de 1812. Nuevos documentos en Revista Chilena de Historia y Geografia, 18 (Santiago, 1915), pp. 107-141.

Vial Correa, Gonzalo, Historia del Senado de Chile (Santiago, Editorial Andrés Bello, 1995).

ZORRAQUín BECÚ, Ricardo, La organización politica argentina en el periodo hispano ${ }^{4}$ (1962, Buenos Aires, Editorial Perrot, 1981). 